\title{
Gonzalo Millán y la subjetividad fragmentada del autorretrato
}

\author{
Gonzalo Millán and the fragmented subjectivity of self-portrait
}

\author{
Biviana Hernández $O$. \\ Estudiante de Doctorado en Ciencias Humanas, Universidad Austral de Chile, \\ Facultad de Filosofía y Humanidades, Valdivia, Chile, \\ e-mail: urganda5@yahoo.es
}

\begin{abstract}
Autorretrato de memoria (2005) expresa la subjetividad fragmentada de un sujeto conforme se representa una individualidad de carácter ordinaria, marginal y degradada; representación que opera mediante el autorretrato, figura que en vez de describir el rostro recrea la experiencia vital del sujeto en las dimensiones que la memoria y ciertas huellas autobiográficas permiten actualizar mediante la escritura poética. Es un texto que contradice estos discursos en el acto de fundar una identidad distópica, tendiente a validar la existencia de una vida mínima (descentrada e impersonal) como parte de una estética de la "objetividad" que viene a sintetizar los principios que definen la obra de Gonzalo Millán.
\end{abstract}

Palabras clave: subjetividad, poesía objetiva, vida mínima, autorretrato, autobiografía, memoria.

Memory's Self-Portrait (2005) expresses the fragmented subjectivity of a subject, according to how to it's represents an individuality of character ordinary, marginal and degraded. Representation to it's realizing through the self-portrait, figure that before of to describe the face to recreate the subject's vital experience in the dimensions that memory and something autobiography footprints to update through the writing. This text contradict those discourses in the act of to found an anti-utopic identity which tends to validate a minimalist life (uncentered and impersonal); an objective esthetic which to came to summarize the rudiments that to define the Gonzalo Millán poetry's. memory.

Key words: subjectivity, objective poetry, minimalist life, self-portrait, autobiography,

\section{INTRODUCCIÓN}

En correspondencia con una cierta poética de la objetividad (Chihuailaf y Eytel 1985), la obra de Gonzalo Millán (1947-2006) indaga en las posibilidades de construcción del sujeto en el contexto de los espacios micropolíticos (Zerán 1994) que identifican las dimensiones pública y privada de la ciudad moderna, espacio físico, cultural y existencial amenazado por el vaivén del tiempo, los objetos y la rutina; referente que bajo la forma de testimonio, serialidad, crítica a la modernidad, reflexión 
metatextual o ecfrásica, deviene un problema complejo de construcción de la mirada a partir de la cual se organiza la subjetividad e identidad del sujeto, cual es la de una voz sin nombre metaforizada en la escritura mediante la descripción de situaciones y objetos tomados de la cotidianeidad.

Ya desde Relación personal (1968) comienza a definirse un sujeto marginal y desarraigado, cuya vida marcará como distópico el sino de su existencia. En este contexto, la preocupación de Millán por los problemas de identificación del yo tiene que ver con una subjetividad fragmentada, en la forma de una voz poética ambivalente y disgregada, en tanto un sujeto anónimo habla de sí mismo a partir de las huellas que otros seres y objetos van dejando en él y que enmascaran hasta disolver su identidad en el texto. De forma tal que éste opera desde la ambigüedad de su propio yo o, bien, desde la polaridad presencia/ausencia con que se reconstruye a sí mismo a través de la escritura (Rojas 2001). De aquel temprano sujeto resulta la presencia reflexiva y autobiográfica del hablante en Autorretrato de memoria; un sujeto de carácter maduro que viene a cerrar un ciclo vital tanto en el terreno personal como poético (Cussen 2006). En este texto se representa la situación existencial de un yo marginal que deambula por el mundo, describiendo desde la neutralidad las percepciones que aquél le sugiere. Así, una vez más sobresalen los objetos de uso en la sociedad industrial, los hábitos, costumbres y ritos de conveniencia diarios del hombre y la pareja, el funcionamiento y degradación de la materia orgánica, así como la transitoriedad y fugacidad de la existencia humana; frentes de sentido de los cuales el sujeto se distancia para criticar cómo en su propia vida ellos lo llevan -a él y al hombre de su tiempo- al apocalipsis de la vida doméstica, que no es sino el caos que implica sobrellevarla dentro de una cierta regularidad tanto personal como social (Foxley 1991; Zaldívar 1998).

En Autorretrato de memoria entonces reaparece la mirada como mecanismo primario de construcción del poema y la perspectiva neutral como recurso de especificación de aquélla. Una mirada que expresa de manera consciente la corrosión existencial de un sujeto que asume la rutina y el tiempo como experiencias de frustración, marginalidad y desarraigo; de allí que ésta extreme el artificio de la acción inherente a ella, al punto que muchos de los poemas semejan simples descripciones de lugares y objetos, lo cual estimula pensar en la forma como se construye la topografía, más que en la identidad de un individuo o los signos que ésta elabora en relación con la figura del autorretrato. En tal sentido, Autorretrato de memoria, de partida, expresa una aparente contradicción: se trata de un autorretrato de memoria, según el enunciado del título, pero en el que no hay descripciones precisas de carácter físico, moral, psíquico u otras, que permitan visualizar la identidad del sujeto, así como tampoco un registro del acontecer lógico-cronológico de su vida pasada que la defina o sitúe temporalmente. En estas circunstancias, transgrede las normas de construcción de los discursos de la autobiografía y la memoria, además de recusar la figura retórica del autorretrato, en un gesto que pone en entredicho los principios convencionales en la escritura del yo. En vista de ello, el texto puede leerse como un breve poemario en el que las relaciones entre vida pasada y vida presente encuentran posibilidades de expresión mediante el simbolismo y la subjetividad de los géneros referenciales (Morales 2001) a los que alude. Sin embargo, las características de la personalidad del sujeto contradicen el propósito fundamental de un relato cuya textualidad se propone como reconstrucción de la biografía y la memoria, ya sea histórica, personal o colectiva de un individuo, en la que se seleccionan y reordenan los hechos pasados 
de una vida, según su devenir temporal, sentido de trascendencia personal y relación con el grupo de referencia. Millán propone un texto en el que la memoria construye un espacio distópico, al saturar de vivencias insatisfactorias los recuerdos que autorizan la significación de la marginalidad y el exilio permanente como rasgos de emplazamiento de la identidad.

Dicho lo anterior, el presente artículo pretende ahondar en las exploraciones intrapersonales que representan la individualidad del sujeto a través de la mirada como acto primordial de aprendizaje y valoración del mundo y de sí mismo, con el objetivo de establecer de qué manera los recuerdos permiten la escritura del yo al sugerir que la memoria no sólo es registro y símbolo, sino también escritura fragmentada de una vida no unitaria, que cree reconstruirse en esa misma fragmentación que más tarde articulará la imagen-identidad en la figura del autorretrato.

De acuerdo con ello, la hipótesis que planteamos sostiene que el sujeto de Autorretrato de memoria legitima la experiencia de una vida mínima en tanto que correlato de un estado de existencia marginal y degradada, mediante la escritura fragmentada del autorretrato y la transgresión de los principios convencionales de dos tipos de discurso: autobiográfico y memorístico, que invierten la figura retórica clásica para mostrar su revés en la forma de un contratexto: autorretrato del silencio o del no decir que conscientemente oculta o desfigura el rostro, en la representación de la distopia que encarna la vida para el sujeto.

\section{LAS ESCRITURAS DEL YO, UNA APROXIMACIÓN DESDE LA AUTOBIOGRAFÍA Y LA MEMORIA}

Desde un punto de vista convencional, quienes han estudiado el problema de la autobiografía (P. Lejeune, G. Gusforf, J. Starobinsky) reducen la figura de autor a la de persona o sujeto real, al definirla como un relato en prosa que un individuo realiza sobre su vida pasada; postulando así una plena identificación entre las categorías de autor (sujeto histórico), narrador y personaje. Identificación que, de acuerdo con P. Lejeune, es producto de un pacto de lectura o contrato de identidad mediante el cual se estable la relación autor-lector:

Por más que en su relación con la historia [...] del personaje el narrador se equivoque, mienta, olvide o deforme, error, mentira, olvido o deformación adquirirán, si se los discierne, el valor de un aspecto entre otros, de una enunciación que, en sí misma, sigue siendo auténtica. Llamamos autenticidad a esa relación interior propia del empleo de la primera persona en el relato personal; no debe confundírsela ni con la identidad, que remite al nombre propio, ni con el parecido, que supone un juicio de similitud entre dos imágenes diferentes realizado por una tercera persona (Cit. en Miraux 2005: 23).

Esta concepción se adscribe a la corriente crítica más tradicional, que plantea el problema de la autobiografía de acuerdo al pacto de lectura como un discurso de verdad para ser leído con este valor. Para Pozuelo, quienes lideran esta línea de interpretación buscarán definir los términos por medio de los cuales la autobiografía articula un tipo especial de discurso que afirma una especificidad, ya sea de índole histórica o pragmática, o en el horizonte de las convenciones genéricas, "toda vez 
que las autobiografías no son novelas, ni la mayor parte de ellas entran siquiera en la categoría de obras literarias" (1993: 186). Mas, ocurre que tal criterio de identidad es puesto en cuestión por María Dolores Vivero, al sostener que éste es sólo una estrategia persuasiva del autor para dirigirse a un determinado público. Dado lo cual, no tendría ninguna relación con referentes históricos:

Lo mismo podemos decir del criterio de verdad. El contrato de autenticidad (que Lejeune llama pacto referencial) le es impuesto al lector desde el principio. El lector puede creerlo o no, pero no es cuestión de parecido con el referente histórico. Ambos aspectos del contrato [...] son inseparables, ambos responden a una estrategia ligada a un contrato de enunciación: digo la verdad (pacto referencial) sobre mí mismo (pacto autobiográfico), porque me sitúo dentro de una jurisdicción narrativa autobiográfica (1992: 415).

Miraux (2005) en tanto sostiene que la autobiografía presupone un pacto referencial que inscribe el texto en el campo de expresión de la verdad, pero que no es equivalente a la verdad de la existencia real, sino únicamente a la del texto; tratándose por tanto de un problema de autenticidad y no de exactitud. Esta mirada define una segunda corriente de interpretación del género, en la medida en que sugiere que toda narración de un yo es una forma de ficcionalización, propia del estatuto retórico de la identidad y en correspondencia con una interpretación del sujeto como eje del discurso. De acuerdo con ésta, en el relato autobiográfico predominará una voluntad creativa más que referencial, de poiesis antes que de mímesis, a la manera de un instrumento no ya de reproducción cuanto de construcción de identidad del yo, en tanto que dicho proceso -en el que se inscribe el espacio autobiográfico- no es solamente de construcción de una identidad en términos semánticos, sino de construcción de una identidad como retórica de la imagen, "como signo para y por los otros. Ese es el fundamento de autojustificación que soporta toda autobiografía" (Pozuelo 1993: 220). Así se explica que en la autobiografía lo que se representa como objeto más que como sujeto sea la identidad que previamente se ha construido en la escritura (Castilla del Pino cit. en Villanueva 1992: 21). A esta corriente también se adscribe Carlos Piña, quien postula el carácter interpretativo de la autobiografía al negar que ésta sea el fiel reflejo de una realidad exterior a ella:

Ni siquiera representa (estadística o simbólicamente) la vida de alguien, sino que se trata de un material relativamente autónomo, que posee un cuerpo propio y que se constituye en algo "nuevo", en el sentido de que no es la consecuencia directa, verbal y discursiva del acontecer histórico de un sujeto (1988: 31).

Volviendo a Lejeune, dos son las condiciones que posibilitan la pertenencia de un texto al género autobiográfico: la identidad entre autor y narrador y la identidad entre narrador y personaje principal. Ambas, de acuerdo con Talens (2000), expresan a su vez dos funciones distintas, pero íntimamente vinculadas entre sí por el uso de la primera persona gramatical: la (auto)construcción de la identidad del yo y la utilización de dicha construcción como mecanismo de validación de la verdad. No obstante, la inscripción del "efecto de verdad" en un relato autobiográfico es una construcción retórica que convierte lo que llamamos normalmente "hechos" en lo que son de verdad "interpretaciones". Ello si aceptamos que el sentido no es inherente a un acontecimiento, así como tampoco éste es atribuido únicamente por quien escribe 
una autobiografía, en la medida en que también el lector participa en su construcción. La postura de Talens está apuntando, en este sentido, a los principios que rigen el contrato autobiográfico definido antes por Lejeune:

Lo que aquí está en juego es una especie de desplazamiento de autoridad, desde el autor y el texto al lector y a su interpretación de ese texto. Tal interpretación está enmarcada por la experiencia vital del lector, incluyendo, en algunos casos [...], la experiencia de leer textos autobiográficos y la reflexión sobre sus pretensiones de verdad [...]. En la autobiografía la perspectiva está restringida al "yo" o a los "yos" de un autor-narrador, en un contrato autobiográfico que incorpora asimismo al autor y al lector (2000: 38).

Por otra parte y de acuerdo con la corriente que concibe la autobiografía como escritura del yo, la memoria constituye una actividad simbólico-discursiva que opera sobre la base de la memoria sicológica, vale decir, sobre aquella que almacena y posibilita los recuerdos en el individuo. Remitiendo en consecuencia a la operación lingüística e interpretativa que éste realiza toda vez que evoca los hechos del pasado, en tanto que "hablamos nuestros recuerdos antes de evocarlos: es el lenguaje y es todo el sistema de convenciones sociales que le son solidarias que nos permite a cada instante reconstruir nuestro pasado" (Halbwachs cit. en Milos 2000: 48). La naturaleza simbólica de la memoria reacciona contra el carácter arqueológico del pasado, en circunstancias que se le concibe como un territorio discursivo en constante proceso de reformulación (Lira 2001). Hace referencia por tanto a otra forma de conciencia sobre la realidad. Esto es así si pensamos que un recuerdo rara vez constituye una idea abstracta o un objeto sin sentido (Milos 2000), antes bien, los hechos que se recuerdan tienen una significación material, asociada a ciertas situaciones que han sido objeto de un razonamiento o afecto. De esta forma, tanto más despliega su potencial subjetivo, cuanto más la memoria explicita el papel creador que cumple el lenguaje en los procesos que semiotizan el pasado o que le otorgan significación, de allí que ésta sea definida por Oyarzún (2001) como un código semántico adscrito a las prácticas sociales del presente, que reinterpreta constantemente el pasado que se recuerda.

Asimismo, el carácter dinámico e interpretativo de la memoria ha sido expresado por Olga Grau, en una concepción que pone de manifiesto la manera como en la construcción de un relato el lenguaje determina y representa el carácter subjetivo de ésta. Así, refiriéndose a la relación que entabla la memoria con el lenguaje y a la que se produce entre el lenguaje y la forma en que éste expresa el sentido de un suceso pasado, descuella la dimensión interpretativa de toda narración:

Muchas cosas han sucedido entre lo acontecido y la actualidad en que el relato se produce, que otorga relieves y comprensiones otras. Lo ocurrido puede llegar a tener interpretaciones distintas a través del tiempo, dando lugar a otros relatos, en relación a los particulares contextos de actualidad. Ello nos habla de que la memoria en cuanto actividad productiva narrativa no sólo está sometida al tiempo, por tanto poseedora de un carácter cambiante, sino que contiene, al mismo tiempo, necesariamente, ficción (2001: 39).

No obstante, si bien estos y otros autores postulan la noción de relato para conceptualizar la memoria o las memorias, en tanto narraciones que interpretan el pasado, ninguno de ellos la define en su calidad genérica o de tipo textual, estableciendo los límites que esta forma de escritura guarda con sus afines: autobiografía, epístola, 
diario, confesión, autorretrato, etc. Ello, debido a que difícilmente estos límites pueden establecerse cuando muchos de los elementos narrativos que los caracterizan son compartidos por todos ellos. Mas, suele considerarse que estos tipos constituyen diversas modalidades del género autobiográfico (Piña 1988). Así por ejemplo, una memoria o un relato de memorias designa, al igual que un texto autobiográfico, un escrito en retrospectiva, en el que una persona "real" narra acontecimientos relevantes de su vida, enmarcados en el contexto de otros eventos de orden político, cultural, en los que ha participado directamente o de los que ha sido testigo (Estébanez 1999). Según esta definición, la frontera que separa la autobiografía de la memoria está dada por el hecho de que, en la primera, el sujeto enunciador acentúa el desenvolvimiento de su personalidad y los hechos que de manera personal han marcado su pasado, siendo el objeto de tratamiento de su relato la historia de su vida individual; mientras que, en la segunda, éste actualiza sucesos de su propia vida, pero situándolos en el contexto de otras vidas y en relación con el acontecer histórico, político o cultural que ha afectado a su país o grupo de referencia. Y si un relato de memorias se distingue de uno autobiográfico por la perspectiva más o menos individualista del sujeto, también se diferencia del autorretrato por el tratamiento temporal de la narración. La memoria retrotrae la vida del sujeto (aun cuando sea sólo un periodo de ella, lo importante es que se reconstruye cronológicamente con cierto detalle y orden lógico), en tanto que el autorretrato describe determinadas características personales del sujeto, ya sea en el ámbito de sus cualidades físicas (prosopografía), como sicológicas, morales e idiosincráticas (etopeya, Fernández 1975, Mortara 2000), características correspondientes a su realidad actual, de allí que esta figura contemple sólo un instante de la vida del sujeto y no el desarrollo de ciertas etapas de aquélla.

\section{AutORRETRATO DE MEMORIA: UNA APROXIMACión DESDE LA AUTOBIOGRAFÍA Y EL AUTORRETRATO}

La autobiografía, desde la tradición que la concibe como un género de no ficción, se define a partir de la correspondencia entre las categorías de autor, narrador y personaje, persona gramatical que a través de la escritura elabora un relato por medio del cual el sujeto reconstruye su vida, a fin de fijarla como testimonio de la verdad y autenticidad de los sucesos ocurridos en el pasado. No obstante, en los 20 poemas de Autorretrato de memoria no existe la perspectiva de un relato retrospectivo de la vida o el principio de verdad, autenticidad o testimonio que subyace a él según esta concepción. En ellos, por el contrario, la vida pasada aparece como un espacio fragmentado de escenas que aluden, sin intentar reconstrucción alguna, a ciertos momentos claves de antaño, pero que no dan cuenta de un tiempo exacto, de una época o periodo concreto de la vida del sujeto y menos aún de una perspectiva que pretenda mitificar o ensalzar la realidad que se recuerda. De tal suerte, el poemario contradice las características esenciales del género al no exponer la vida pretérita conforme una secuencia cronológica, que exalte sucesos representativos de la vida personal o del acervo común de experiencias compartidas por una colectividad. En este sentido, la obligada identidad que proponen los teóricos de cuño más tradicional entre las categorías de autor, narrador y personaje, son cuestionadas y a la postre anuladas por Millán. A este respecto, conviene recordar que la obra poética del autor está signada 
por un sujeto que constantemente toma distancia del espacio referencial, en su afán por contemplar el mundo en una suerte de voyerismo vital, que recuerda el principio de la objetividad como cuestión de exterioridad y ajenidad. De la serie, "Autorretrato recordando" representa dicho afán a través del ejercicio de la mirada, que articula la descripción en base a la ambigüedad que sugiere la analogía entre los verbos recordar y despertar, por cuanto, tratándose de un retorno fugaz al pasado, la caducidad de la escena que describe no aparece claramente especificada en el texto. Veamos:

Las onduladas láminas del colapez

La masilla fresca en los vidrios recién puestos

La creta en polvo para pulir el juego de peltre

El lavatorio con amoníaco para lavar

Las peinetas flotantes como peces de celuloide

Rincones inalcanzables con grumos de cera

Color cereza, como la gomina Glostora

El empapelado de la escalera

Detrás del cual se oía caer la arena

La oscilación del péndulo en el silencio

La grieta voraz entre las tablas del piso.

Un caído cadete de plomo con penacho blanco

El embriagador esmalte granate de las uñas

El frasco azul de la leche de magnesia

El trapito con un cubo de azul en la artesa

Los dorados filamentos del dulce de alcayota

El hervor del agua oxigenada en contacto con la sangre.

(p. 16)

En su condición de sujeto poético -si lo vemos en correspondencia con las categorías de narrador o de personaje- éste pervive sólo en relación con una perspectiva de observación neutral que rara vez se corresponde con la partícula gramatical del yo o del nombre. En consecuencia, su aparente no identificación -en tanto que negación de los discursos que recrean la vida de un yo- aparece como un mecanismo de encubrimiento de la propia identidad, toda vez que la personalidad resulta carente de sentido moral, el cuerpo, al parecer, inexpresivo y los recuerdos (pertenecientes a la memoria individual), desprovistos de unidad e interrelación. La reconstrucción de la vida en este texto dice relación entonces con el valor existencial que le atribuye el sujeto, a saber: la apatía y el rechazo que experimenta hacia las concepciones de la identidad en tanto que pertenencia social, aun cuando en el último de sus autorretratos numerados (“\#500 (Como Miles)”), termine identificándose con los de su especie al reconocer la dimensión colectiva que unifica la convivencia de los hombres en sociedad; identificación que en el conjunto del poemario bien colectiviza la significación individual de su yo marginal, expandiéndola a los otros como una resonancia del determinismo universal que opera en los espacios socializados de los discursos de la identidad. Es de estos espacios de los que justamente descree Millán.

Este autorretrato es el que mejor expresa una imagen de sí mismo, toda vez que el sujeto se describe de acuerdo a rasgos físicos hiperbólicos, con el propósito de que éste se transforme más que en un retrato en una caricatura del rostro, a partir de la cual sea leída su vida y entendida su personalidad, pero, sobremanera, desde la que 
se estimule repensar los sentidos de la identidad y la importancia que puede proyectar la presencia/ausencia de un nombre en la idea de un yo como figura de facto:

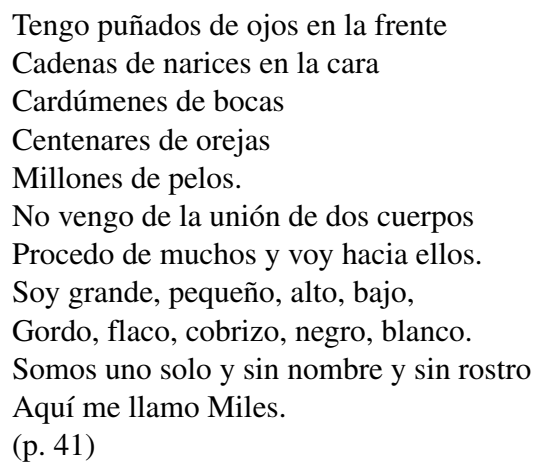

Sin embargo, pese a la existencia de algunos atisbos de identidad personal, no hay un autorretrato en que exalte su figura o narre algún episodio "relevante" para un grupo de individuos (los recuerdos agradables, que recrean situaciones de afecto experimentadas en su infancia, son escasos). Del mismo modo, se rodea siempre de situaciones ordinarias que autorizan la descripción de lugares marginales, degradados e imperfectos; descripciones que atribuyen al autorretrato un acentuado carácter desmitificador de los espacios públicos y privados, tanto como de los recuerdos en que se actualiza la visión de ciertas figuras familiares, como ocurre frecuentemente con la madre, la que es percibida como un símbolo de condena y muerte. Nótese, por ejemplo, su impronta fatal en la connotación perversa de la sangre que opera en "Recado bajo un magneto en un refrigerador Crosley":

\author{
Mami, \\ La próxima vez \\ No manches por favor \\ Mi cepillo de dientes \\ Con sangre \\ (p. 18)
}

El breve texto explicita una situación de contacto cotidiana y familiar a través de un recado personal, que si bien parece insignificante, alude a la situación compleja que representan para el sujeto la sangre y el cepillo de dientes. Por un lado, la anécdota sitúa a la madre como portadora de la mácula que obstruye la inocencia e ingenuidad del hijo, al manchar con su sangre el objeto por antonomasia privado de los hombres. Esta mancha es la que condena al inocente provocando su infelicidad: la violación de su espacio sagrado en la transgresión de su privacidad, hecho que a la postre termina corroyendo su vida en las dimensiones más profundas, puesto que desestabiliza y, en última instancia, anula su identidad personal. De allí que la sangre de su progenitora metaforice la dimensión inevitable y premonitoriamente dolorosa de la vida de un sujeto inerme ante las posibilidades de acendrar la tragedia de aquel vínculo fatal. El poema evidencia el propósito de utilizar objetos que lo neutralicen en la escritura, de modo tal que la descripción parezca algo distinto a lo que sería un relato de vida 
en sentido convencional. En relación con el texto, éste no explica por qué su madre representa una figura destructiva, prefiere simplemente connotar, mediante la imagen del cepillo de dientes, cuán profunda es la herida que le ha causado su influjo. Del mismo modo que su discurso tampoco se propone como autentificación de una imagen verdadera de sí que lo represente o testimonie, aspecto que explica su disgregación en (anti)autorretratos que fragmentariamente confirman su voluntad de identificación desde la frustración y corrosión que caracterizan su yo, en las dimensiones que abarcan desde lo existencial a lo poético.

Este sujeto no tiene nombre, origen, profesión o residencia, y aunque haga mención de lugares donde pudo haber vivido o a personas cercanas a él (nombradas casualmente, a excepción de la madre, sin que en ellas se exprese un compromiso afectivo real o en profundidad), los rasgos con que se describe no hablan de la imagen de un yo según características físicas, morales o idiosincráticas que justifiquen la escritura de un autorretrato. Por el contrario, la apariencia de aquél, que hace dialogar su disgregación y fragmentación con el "aquí" -espacio físico-existencial vacío, mínimo y carente de afecto- identifica la amarga naturaleza de su ser moral y entorno social; estado que notablemente recrean algunos de los autorretratos numerados, como "\#051 (Como el perro de Goya)", "\#078 (Con una máscara de tortuga)", “\#110 (Vacío)” o "\#180 (Provecto)", siendo quizá “\#347 (Aproximado)" el que mejor dé cuenta de su estado existencial al mostrar cómo, tocado hostilmente por los efectos del tiempo, su vida ha estado marcada por la soledad, en circunstancias que simbólicamente alude al rostro como metáfora de la desolación y al abandono que sugiere la idea de un desierto:

Aquí el contorno de la figura se pierde.

La nitidez deja de ser lo que fue,

Esfumada por el halo del color.

El valor de la línea se empaña y decae.

El rostro invadido por el tiempo

Destaca el pómulo huesudo,

Las ojeras infladas y porosas,

Las arrugas y orejas peludas.

Entre una ventanilla y otra de la nariz,

Se extiende un Sahara.

Entre los ojos hay un desierto de Atacama.

(p. 40)

Y si bien las figuras humanas que retrotrae conllevan signos de dolor y amargura, los espacios públicos de referencialidad (calles, barrios, paraderos), en los escenarios micropolíticos de la cotidianeidad, participan de un cierto sentido de trascendencia o por lo menos de afectividad para el sujeto, en la medida en que afirman su arraigo a un sentimiento mínimo de pertenencia, es el caso de los autorretratos en que recuerda el barrio la Chimba, el cine Recoleta y sus paraderos, todos ellos ambientes en que transcurrió su infancia:

La primera vez que fui al cine sin mis padres fue al Cine Recoleta.

Fueron también mis primeras funciones de rotativo, tardes enteras con

Dos o tres películas y una bolsa de guindas secas.

Fue también el primer encuentro con la fauna de los biógrafos de barrio. 
Las primeras metamorfosis del hombre lobo, los gritos y las tallas,

Las obscenidades impunes en la oscuridad (...)

Por primera vez entre compañeros del colegio y entre conocidos y

Desconocidos, fuera, lejos de casa, en otra parte.

El pelo y los pantalones cortos con copetes de chincoles.

En el gabinete de la memoria (gabinete del doctor Caligari) ciertos cines (hoy desaparecidos) conservan sólo ciertas películas.

Me gustaban las cintas de guerra, el circo romano, las matanzas

y masacres indiscriminadas.

Era un admirador de Atila y Gengis Khan.

Prefería los vaqueros rudos (Randolph Scott, Gary Cooper)

a los vaqueros cantores (Gene Autry y Roy Rogers) (...)

Soñaba por las noches que era el hombre invisible

y por las tardes que era Robinson Crusoe.

Jugando a los piratas temía a los caníbales y leprosos de los

Mares del Sur (...)

Allí me reía con Cantinflas y Jerry Lewis y me divertía con Mister Ed el caballo parlante.

En el Cine Recoleta (que hoy es un garaje) entre los fierros de un Spider De plata, aún vive James Dean.

Y en medio del estruendo de la vulcanización, pena el Rock del Reloj de Bill Halley y sus cometas mientras desabollan El Dorado Cadillac

Púrpura de Elvis.

(“Autorretrato a la salida del Cine Recoleta”, p. 24-5).

Mas no ocurre lo mismo en el caso de situaciones que aluden a las costumbres y tradiciones culturales del país. Éstas carecen de valor para él, toda vez que aúnan características del autoritarismo que implica la visión de la identidad como reducto estatuido para el control del comportamiento humano. Identidad aquí es símil de violencia, un ghetto de poder en la exigencia de "normalidad" para el ejercicio de la vida cívica y ciudadana, de allí que eludirla, contradecirla o negarla sea el acto por excelencia para claudicar un emplazamiento de resistencia. Es lo que ocurre en el gesto de la huida de "Autorretrato ecuestre", en el que recusa la idea de un compromiso social con la identidad nacional en el recuerdo y encomio de las tradiciones culturales. Reacción que pone en evidencia su rechazo hacia la idea de patria o nación, así como de los arquetipos culturales creados por el imaginario popular:

Huyo de huasos, gauchos y charros,

De quijotes y llaneros solitarios

Soy un centauro de potrillo y niño

Embalsamado en el gesto de la huida

Huyo de la amenaza de un septiembre

Todo el año con el mismo cacho de chicha

Y las palmas de las cuecas trágicas en falsete

Zapatean los cascos que se evaden.

Huyo del Guatón Loyola y la Comadre Lola.

Deserto del Cuadro Verde

Y la Real Policía Montada del Canadá. 
Mi caballo tiene mil nombres y colores,

Es el albino caballo de Napoleón

Relinchando con furiosa locura.

Tiene los mil visos del espejismo

Y la polvorosa mentira.

Pegaso, Clavileño, Ñandú, Ketchup.

Se evade en reversa perdidos los estribos

Galopando de la meta al punto de partida (...)

Huyo de mi familia de héroes y tumbas

Y de las paradas militares todos los días.

Huyo de la violenta sombra de la estatua.

Huyo de la medialuna de arena consagrada

Donde se despanzurran los novillos

Y sangran las bellas bestias espoleadas.

(p. 31-2)

\section{AutorRetrato DE MEMORIA: UNA APROXIMACIÓN DESDE LA MEMORIA Y EL AUTORRETRATO}

Si la memoria constituye por excelencia la facultad del hombre para verse a sí mismo, en tanto que mecanismo de representación, el sujeto la utiliza para articular su experiencia de vida conforme la significación que revisten los fragmentos que de aquélla condensan sus etapas más significativas, ya en lo circunstancial y material como en los hechos traumáticos de un periodo que marca la historia política de Chile en 1973. En este sentido, la fragmentación del autorretrato opera la escisión misma de la vida del sujeto en el devenir temporal que reclama su efectuación poética, un acto que responde al interés de Millán no sólo por lo intrapersonal, sino también por la validez que una existencia o una vida "mínima" puede adquirir en el contexto de la escritura.

Los fragmentos de vida que éste reconstruye semejan el collage de una memoria escindida que busca generar espacios de reflexión y autodefinición, en relación con la experiencia del exilio y, en este ámbito, con el significado que tras ella adquiere la ansiada pero no menos traumática situación del retorno a la patria. Sirva el poema "Autorretrato en Valparaíso" para ejemplificar lo anterior:

Ahora es la hora del áncora

$\mathrm{Y}$ de engranar en el cielo azul

Con frases cortas como pinceladas

Para iluminar la harina y el hilo.

El mar y los cerros

Son como las crestas

Y senos de una misma onda.

La calle que sube y la calle

Que baja son la misma cosa.

El barco que zarpa

No es el mismo barco que regresa

(p. 43) 
La búsqueda de estos espacios gira en torno a reflexiones no sólo de tipo históricas, sino también sociales, en que el sujeto critica los poderes alienantes de la modernidad, así como las estructuras jerárquicas del mundo de mercado, que en el ámbito de las relaciones humanas establece la coexistencia de clases sociales diferenciadas. "Autorretrato con Susana y los niños" da perfecta cuenta de esta situación, al observar cómo el destino de nana que le tocó vivir a la anciana Sofía, producto de cierta predeterminación social, determina el lema que lo (auto)representa: la vida no existe cuando es una cosecha que ya tiene bodega.

El sujeto utiliza la memoria individual recuperando aleatoriamente escenas dispersas tomadas de la cotidianeidad, inscritas y desarrolladas en un devenir temporal, para articular los modos de representación del yo. Trátase por tanto de un acto fundamental de expresión, ya que si bien como género (es decir, como reducto de autoridad-autoritarismo) la memoria es cuestionada por Millán, le permite al sujeto significar la realidad otorgándole sentido al pasado y a partir de aquél una valoración que legitime su estado actual de existencia. En consecuencias, ella constituye su locus de enunciación privilegiado, lugar donde elabora las significaciones y reinterpretaciones de lo pasado que, más tarde, posibilitarán una determinada percepción de la realidad y finalmente la configuración de una vida actual. Siendo así, los autorretratos en que se representa validan la arbitrariedad y parcialidad de la mirada, acto que opera el ejercicio de la memoria en el intento por captar la temporalidad que fija la posición del sujeto que rememora (Zambra 2005). En el poema "Con foto de luto (Aetatis sua: 20 años)" se percibe un claro distanciamiento temporal, no obstante íntimamente vinculado por la significación de un suceso particular que connota la realidad del sujeto:

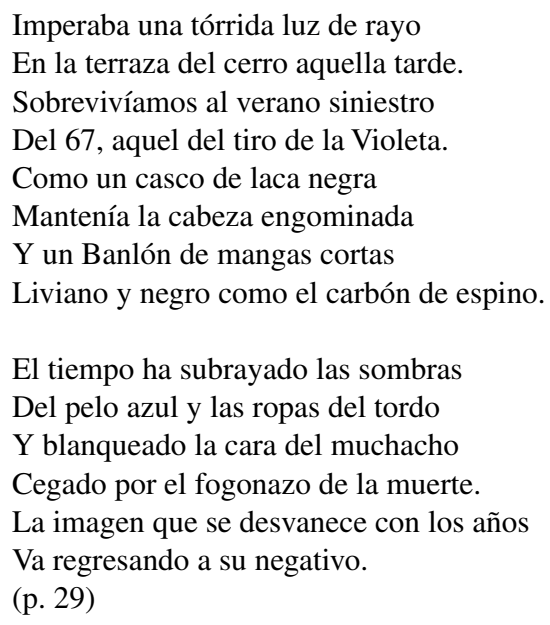

Este recuerda el verano del año 67, manifestando con cierto detalle, al explicitar la edad que tenía en aquel momento -que coincide con la edad real que tendría Millán en ese año- una situación específica de su vida pasada: la fotografía que congeló su dolor por la muerte de Violeta Parra, fogonazo de la temporalidad por haberlo capturado en la imagen y en el recuerdo que implica su fijación. Esta muéstrale en el presente cómo la disolución de la imagen grabada en la fotografía retrotrae la esencia de su negativo, que no es sino el mismo dolor o el luto de aquellos años, pero ahora nutrido 
por el fogonazo de sus propias agonías y la cercanía de su propia muerte. El poema constituye así una evidencia más del uso indirecto y fragmentario que usa el sujeto para hablar de su propia vida, cúmulo de fragmentos que escenifican las situaciones cotidianas de donde extrae los referentes para la construcción de este gran autorretrato que de suyo implica la memoria.

El presente del sujeto millaniano, por ende, no constituye la memoria de un pasado trascendental o de un contexto político-social específico. Es memoria de una infanciaadolescencia marcada por escenas -como señala él mismo en uno de sus autorretratos, poco originales-. No obstante, en ellas está impregnado el valor de una vida mínima, constituyendo las escasas huellas que lo identifican no sólo con el pasado, sino también con el presente y que lo definen en relación con ambas temporalidades. De tal suerte, lo que el sujeto recupera de su pasado, mediante imágenes y recuerdos dispersos, son fragmentos de escenas que descubren de qué manera se percibe a sí mismo y cómo esta autopercepción actualiza desde el presente un sentido que posibilita su autodefinición; o, si se quiere, la representación de su propia individualidad. En "Autorretrato como pichón de paloma" se muestra análogo a un ser pequeño e indefenso frente al mundo, cuyo cuerpo, salvo el corazón, al estar cubierto prematuramente de plumas de paloma, semeja un niño que antes de tiempo ha debido madurar y hacerse adulto para enfrentar el caos de la existencia humana, así se explica que en su nido cagado deba destacarse sobre un fondo de tinieblas por su plumosa palidez de grisalla. Lo mismo se observa en "Autorretrato con calavera" al percibirse la fragilidad que encarna frente a esta figura, personificación de la muerte que le otorga una segunda morada con rostro amable, pero de manera provisoria, pues semejante a un caracol, símbolo de fertilidad y regeneración periódica (Chevalier y Gheerbrant 1999), ésta se halla vacía. La imagen, por tanto, viene a materializar la confirmación de que vida y muerte no sólo son homólogas en su vacuidad, sino también en su sentido de insatisfacción e intrascendencia espiritual:

Estoy sentado en las rodillas huesudas

De una calavera

Vestida con largas ropas de mujer.

Hay pulseras con monedas de oro

Tintineantes en sus muñecas flacas.

Anillos con piedras preciosas ensartan

Los huesos finos como las patas de un pájaro.

Collares de dientes de leche cuelgan del cuello espinudo.

Los pequeños huesos de los pies

Están calzados por menudos escarpines

La calavera sonríe sin boca y sin labios.

Sonríe orgullosa mirando el esqueleto

Del niño nonato acunado en su regazo.

Estoy tan leve en sus manos

Como las migas de una hostia,

Amparado cual esqueleto de una hoja

O un caracol vacío.

(p. 37) 
Conforme lo anterior, diremos que recordar constituye el recurso fundamental que el sujeto utiliza para referirse a determinados momentos de su pasado, en la posibilidad (reivindicativa para la construcción de una vida mínima) de resignificarlos desde la subjetividad que implica valorar lo pasado como presente, y desde las posibilidades que tiene la memoria en su dimensión síquica y discursiva para reconstruir aunque sea una imagen provisoria, esporádica o momentánea de sí, a través de una mirada neutral frente a los espacios públicos y privados de la cotidianeidad. Por otra parte, haciendo uso de esta facultad, el sujeto puede expresar su medianía como una figura escindida en un espacio físico-existencial descentrado, cuyas vivencias inscriben la vacuidad de su yo como horizonte epistemológico, esto es, como autorrepresentación $\mathrm{y}$, por ende, posibilidad de autoconocimiento. De hecho, Autorretrato de memoria nos invita a interrogar las fuentes de sentido de las que se echa mano para hablar de sí mismo en la poesía chilena postgolpe militar; en última instancia, de los motivos que sustentan el oficio de un poética de la objetividad como quiere Millán para la escritura de los '60 en Chile (Zerán 1994).

En este contexto, la memoria personal, aunque fragmentada, tiene la capacidad de reconstruir ciertos momentos de la experiencia vital de este sujeto, develando de qué manera su conciencia y percepción del mundo participan de la frustración y marginalidad del propio yo; aspectos que la escritura actualiza mediante la fragmentación de la propia vida en tanto que correlato de la ausencia o negatividad de un autorretrato a la usanza retórica, donde se describe la escena "completa" -aunque parcial- de un rostro humano. En estas condiciones, si los autorretratos en que se reconstruye el sujeto para deconstruirse a sí mismo cuestionan las características fundamentales que definen un relato autobiográfico, los rasgos que determinan su personalidad y condiciones de existencia material también transgreden la dimensión social y colectiva que define el género memoria. Por tanto, al tiempo que ésta activa la escritura, en paralelo acentúa la convivencia de rasgos que hacen discordantes y que corroen hasta su disolución las convenciones escriturales que ambos géneros establecen. Tratándose de una escritura donde autorretrato y memoria secundan un punto de vista crítico-reflexivo respecto a los supuestos epistemológicos y culturales que aquéllos suponen.

Dada esta realidad, las situaciones de vida que el sujeto recrea, ya como recuerdos de hechos vividos, representación de los objetos de la cotidianeidad o ya como metáforas de sí mismo, emplazan la escritura del yo como acto de resistencia contra la idea de identidad y, por extensión, de todo género convencional donde se represente al individuo; espacios de control y autoridad de los que el poeta puede evadirse a través de una escritura, en que el yo siempre aparece enmascarado o encubierto detrás de los objetos que lo desplazan a un lugar sin nombre. Pero más o menos travestido siempre aparece. Más allá o más acá de los límites que le impone la temporalidad, su ausencia siempre conlleva la presencia del otro que lo representa. Así en el juego de querer ocultarse pero a medias o en el dejarse ver en alguna zona del hueco que se yergue sobre una poesía que destaca por su frialdad y escepticismo. El sujeto se desplaza, se esconde, evádese del autorretrato, imagen del yo impositiva y autoritaria, como lo es cualquier signo que corresponda al imaginario de la identidad. Por eso la memoria se burla del escrito en retrospectiva, de las identificaciones generacionales y temporales, de los recuerdos colectivos; su lugar es el espacio que suelda no la identidad sino la causalidad que determina la experiencia de vida de un sujeto cuya mirada es el relato vario de una escritura que para hablar de una individualidad sólo 
puede acudir a un estética de la fragmentación. De allí que al querer encubrirse pero a medias, en el intento de ocultar su rostro para contradecir la figura del autorretrato, los poemas de Autorretrato de memoria, en mayor o menor grado, lo definan en el ámbito de la etopeya, al esbozar una visión de sí mismo a través de la actitud anodina constante que manifiesta y que comúnmente está asociada a imágenes que revelan la percepción que de sí tiene en el momento que escribe: el caracol vacío, la sanguijuela de la muerte o la máscara de tortuga, por mencionar sólo las más relevantes.

\section{PARA CONCLUIR}

Autorretrato de memoria opera el tránsito que va de la mediación retórica de un sujeto romántico a una subjetividad fragmentada mediante la neutralidad de una mirada impersonal, que retrotrae ciertos hechos de la vida pasada para confirmar un estado actual de existencia marginal y degradada en la representación de los objetos, imágenes y escenas de la cotidianeidad. En este contexto, aflora lo intrapersonal como espacio de posibilidad para la escritura poética, un ámbito de exploración para una estética de la fragmentación, pero también de resistencia y cuestionamiento hacia los discursos de la identidad (personal y colectiva) que erigen, en la retórica convencional, la escritura de una memoria, autobiografía o autorretrato.

Una vida mínima, conforme las características materiales de los espacios públicos y privados de la ciudad y los rasgos existenciales del sujeto, es lo que representa una poética de la individualidad que se vale de la figura del autorretrato como estrategia de encubrimiento lúdica para la autorrepresentación del yo. De allí que esta voluntad subversiva contra los géneros llamados referenciales actualice la imagen de uno ojo reconstruido, como unidad poética de la fragmentación de una presencia que mira o de un anti-sujeto que se construye como un yo disperso, disgregado o desplazado en una mirada que no respeta el orden del tiempo en la descripción de los hechos ni los principios retóricos tradicionales en la escritura de un autorretrato.

Desde esta perspectiva, la mirada actúa entonces como estrategia de ocultamiento y resistencia contra la idea de identidad; en la apuesta por una escritura fragmentada del autorretrato en tanto que voluntad activa para validar una existencia mínima. Es así que la memoria tiene la capacidad de registrar la situación de los objetos de uso, al tiempo que erigir un espacio de reflexión crítica en torno a las condiciones de existencia del hombre citadino moderno. De tal suerte, los autorretratos millanianos no se definirán como textos en los que el sujeto se describa a partir de características físicas o de rasgos morales o ideológicos, sino como fragmentos de un cuerpo que se reconstruye a través de una mirada introspectiva de sí, desde una perspectiva espacio-temporal que hace que los recuerdos actúen como características o valores determinantes de su individualidad. Aquí la negación o negatividad de la figura retórica clásica, tanto como del imaginario de la identidad, emplaza también el lugar subjetivo de la mirada que se quiere neutral: se trata siempre de un lugar diatópico, ya de la palabra, la poesía o la vida. 


\section{OBRAS CITADAS}

Cabo, Fernando. 1992. "Autor y autobiografía”, en Romera et al. Escritura autobiográfica. Madrid: Visor.

Cussen, Felipe. 2006. “Identidades fragmentadas y reconstruidas". Revista Universitaria $\mathrm{N}^{\mathrm{o}} 89$.

Chevalier, Jean y Alain Gheerbrant. 1999. Diccionario de los símbolos. Barcelona: Herder.

Chihuailaf, Elicura y Guido Eytel: "Gonzalo Millán: un poeta objetivista". Poesía Diaria 6, año II, mayo de 1985, Temuco, Chile, p. 17.

Estebánez, Demetrio. 1999. Diccionario de términos literarios. Madrid: Alianza.

Grau, Olga. 2001. "Lenguajes de la memoria”, en Raquel Olea y Olga Grau (comp.). Volver a la memoria. Santiago de Chile: Lom.

Fernández, Pelayo. 1975. Estilística. Estilo, figuras estilísticas, tropos. $5^{\text {a }}$ edición. Madrid: José Porrúa Turanzas, S.A.

Foxley, Carmen. 1991. "La negatividad productiva y los gajes del oficio", en Carmen Foxley y Ana María Cuneo. Seis poetas de los sesenta. Santiago de Chile: Universitaria.

Lira, Elizabeth. 2001. "Memoria y olvido", en Raquel Olea y Olga Grau (comp.). Volver a la memoria. Santiago de Chile: Lom.

Milos, Pedro. 2000. "La memoria y sus significados", en M. Garcés et al. Memoria para un nuevo siglo. Chile, miradas a la segunda mitad del siglo XX. Santiago de Chile: Lom.

Millán, Gonzalo. 2005. Autorretrato de memoria. Santiago de Chile: Universidad Diego Portales.

—. 1997. Trece lunas. Santiago de Chile: Fondo de Cultura Económica.

—. 1994. La Ciudad. Santiago de Chile: Cuarto Propio.

Miraux, J. Philippe. 2005. La autobiografía. Las escrituras del yo. Buenos Aires: Nueva Visión.

Morales, Leonidas. 2001. La escritura de al lado. Géneros referenciales. Santiago de Chile: Cuarto Propio.

Mortara, Bice. 2000. Manual de retórica. María José Vega (trad.). $3^{\text {a }}$ edición. Madrid: Cátedra.

Oyarzún, Kemy. 2001. "Des/memoria, género y globalización”, en Raquel Olea y Olga Grau (comp.). Volver a la memoria. Santiago de Chile: Lom.

Piña, Carlos. 1988. "Verdad y objetividad en el relato autobiográfico”, en Jorge Narváez (ed). La invención de la memoria. Santiago de Chile: Pehuén.

Pozuelo, José María. 1993. Poética de la ficción. Madrid: Síntesis.

Rojas, Waldo. 2001. "Gonzalo Millán: motivos y variaciones para la revisita de su poesía reunida". Poesía y cultura poética en Chile. Santiago de Chile: Universidad de Santiago.

Skármeta, Antonio. "Relación personal, por Gonzalo Millán" (reseña), Revista Chilena de Literatura 1, otoño de 1970, pp. 91-95.

Talens, Jenaro. 2000. El sujeto vacío. Cultura y poesía en territorio Babel. Madrid: Cátedra.

Villanueva, Darío. 1992. "Realidad y ficción: la paradoja de la autobiografía", en Romera et al. Escritura autobiográfica. Madrid: Visor.

Vivero, María Dolores. 1992. "Enunciación y discurso autobiográfico: el ejemplo de Gide", en Romera et al. Escritura autobiográfica. Madrid: Visor.

Zaldívar, M. Teresa. 1998. La mirada erótica: Gonzalo Millán/Ana Rosseti. Santiago de Chile: RIL.

Zambra, Alejandro. "Autobiografía de miles". Taller de letras, $\mathrm{N}^{\circ}$ 37, 27 de septiembre de 2005, pp. 181-4.

Zerán, Faride. 1994. "La sobredosis de Gonzalo Millán”, Literatura y Libros, La Época, 28 de agosto, p. 5. 